\title{
Comparison of the local pivotal method and systematic sampling for national forest inventories
}

Minna Räty ${ }^{1 *}$, Mikko Kuronen ${ }^{1}$, Mari Myllymäki ${ }^{1}$, Annika Kangas $^{2}$, Kai Mäkisara $^{1}$ and Juha Heikkinen ${ }^{1}$

\begin{abstract}
Background: The local pivotal method (LPM) utilizing auxiliary data in sample selection has recently been proposed as a sampling method for national forest inventories (NFIs). Its performance compared to simple random sampling (SRS) and LPM with geographical coordinates has produced promising results in simulation studies. In this simulation study we compared all these sampling methods to systematic sampling. The LPM samples were selected solely using the coordinates (LPMxy) or, in addition to that, auxiliary remote sensing-based forest variables (RS variables). We utilized field measurement data (NFI-field) and Multi-Source NFI (MS-NFI) maps as target data, and independent MS-NFI maps as auxiliary data. The designs were compared using relative efficiency (RE); a ratio of mean squared errors of the reference sampling design against the studied design. Applying a method in NFI also requires a proven estimator for the variance. Therefore, three different variance estimators were evaluated against the empirical variance of replications: 1) an estimator corresponding to SRS; 2) a Grafström-Schelin estimator repurposed for LPM; and 3) a Matérn estimator applied in the Finnish NFI for systematic sampling design.
\end{abstract}

Results: The LPMxy was nearly comparable with the systematic design for the most target variables. The REs of the LPM designs utilizing auxiliary data compared to the systematic design varied between $0.74-1.18$, according to the studied target variable. The SRS estimator for variance was expectedly the most biased and conservative estimator. Similarly, the Grafström-Schelin estimator gave overestimates in the case of LPMxy. When the RS variables were utilized as auxiliary data, the Grafström-Schelin estimates tended to underestimate the empirical variance. In systematic sampling the Matérn and Grafström-Schelin estimators performed for practical purposes equally.

Conclusions: LPM optimized for a specific variable tended to be more efficient than systematic sampling, but all of the considered LPM designs were less efficient than the systematic sampling design for some target variables. The Grafström-Schelin estimator could be used as such with LPMxy or instead of the Matérn estimator in systematic sampling. Further studies of the variance estimators are needed if other auxiliary variables are to be used in LPM.

Keywords: Auxiliary data, Bias, Local pivotal method, Matérn estimator, National forest inventory, Sampling efficiency, Simple random sampling, Spatially balanced sampling, Systematic sampling, Variance

\footnotetext{
* Correspondence: minna.raty@luke.fi

${ }^{1}$ Natural Resources Institute Finland (Luke), PO Box 2, FI-00791 Helsinki,

Finland

Full list of author information is available at the end of the article
}

\section{Springer Open}

(c) The Author(s). 2020 Open Access This article is licensed under a Creative Commons Attribution 4.0 International License, which permits use, sharing, adaptation, distribution and reproduction in any medium or format, as long as you give appropriate credit to the original author(s) and the source, provide a link to the Creative Commons licence, and indicate if changes were made. The images or other third party material in this article are included in the article's Creative Commons licence, unless indicated otherwise in a credit line to the material. If material is not included in the article's Creative Commons licence and your intended use is not permitted by statutory regulation or exceeds the permitted use, you will need to obtain permission directly from the copyright holder. To view a copy of this licence, visit http://creativecommons.org/licenses/by/4.0/. 


\section{Background}

National Forest Inventories (NFI) commonly use systematic sampling where the random location of one sample plot defines the locations of the other sample units according to the chosen design. As a result, the sample units are arranged according to a predefined pattern (such as a square grid) over the inventory region (Tomppo et al. 2010; Vidal et al. 2016). Further, for cost efficiency reasons, the sample plots are typically arranged in clusters. The uniform coverage of the inventory region achieved with systematic sampling is generally anticipated to yield more efficient estimators of the mean or total values of forest variables than simple random sampling (SRS) of clusters (e.g. Magnussen et al. 2020). In addition, SRS may result in large gaps without sample plots, which is particularly problematic when estimating means or totals for small sub-domains of the inventory region.

The utilization of remote sensing data has a long tradition in forest inventories (Kangas et al. 2018). Satellite images have been applied for the Finnish multi-source National Forest Inventory (MS-NFI) since the 1990s to produce wall-to-wall maps of forest resources and municipality-level statistics (Tomppo et al. 2008). MSNFI maps produced as a result of earlier NFI campaigns offer spatial information which can be utilized as prior information in the sampling design and estimation for a new NFI.

Most of the recent efforts to enhance NFIs with auxiliary data have concentrated on the estimation phase. Both model-based and model-assisted methods, including post-stratification as a special case, have been developed (Särndal et al. 1992; Opsomer et al. 2007; Gregoire et al. 2011; Tipton et al. 2013; McRoberts et al. 2013; Magnussen et al. 2015; Saarela et al. 2015; Kangas et al. 2016; Ståhl et al. 2016; Myllymäki et al. 2017; Haakana et al. 2019). However, the emergence of the local pivotal method (LPM, Grafström et al. 2012), enabling approximately balanced sampling in a multidimensional data space (Grafström and Lundström 2013), has also stimulated attempts towards the direct use of auxiliary data for more efficient sampling designs (Grafström and Ringvall 2013; Grafström and Schelin 2014; Grafström et al. 2017). MS-NFI maps have been used in Finnish NFI since the1990s to specify the details of a systematic cluster sampling design, such as the number of plots in a cluster and the distance between them. In addition, it has been used to implement double sampling for stratification in the sparsely forested northernmost part of the country (Tomppo et al. 2011).

Promising results have been reported concerning the potential of LPM to improve large-scale inventories, but the data used in these studies has caused some limitations. In Grafström et al. (2017), for instance, no independent auxiliary data were available, but the target variables were sampled utilizing other variables of the same remote sensing material. In Räty et al. (2018) the auxiliary data was independent, but the population was limited to the real NFI sample plot positions in the target data, which meant that clusters could not be closer than about $7 \mathrm{~km}$ from each other. Furthermore, LPM was not compared to systematic sampling in these studies.

Methods for improving the efficiency must be equipped with a proper, practically applicable estimator of uncertainty in order to be able to report the inventory results with the improved precision. Design-unbiased estimators of variance, the most commonly accepted measure of uncertainty (e.g. Gregoire 1998), are not available for either systematic sampling (e.g., Magnussen et al. 2020) or LPM (Grafström and Schelin 2014). Many NFIs use the variance estimator associated with SRS, based on the argument that it should "safely" overestimate the uncertainty due to sampling. However, this means that the improvement achieved by applying a more efficient sampling design will not be reflected in the reported uncertainties.

A variance estimator associated with SRS is based on the differences in the values of the target variable in the individual sampling units from the overall mean. The idea of reducing the overestimation by replacing these differences with local differences computed within groups of adjacent sampling units was already adopted in the first Nordic NFIs (Lindeberg 1924; Langsaeter 1926). Wolter (1984) gives a review of the later development of such approaches and a recent application can be found in Ene et al. (2013). A generalization of onedimensional local difference estimators to spatially systematic sampling was introduced into forest inventories by Matérn (1947) and has been routinely used in the Finnish NFI since the 5th NFI (Salminen 1973; Heikkinen 2006).

The approximate variance estimator for the LPM, proposed by Grafström and Schelin (2014) and Grafström and Matei (2018) is similar to the local difference estimators used with systematic sampling. In previous studies, the approximate variance estimator has worked well (Grafström and Schelin 2014; Grafström and Matei 2018). However, the study areas have been small and generalization of results for NFI estimation where results are reported at regional level has not been shown. Nor have these studies utilized auxiliary data that would be available in a modern NFI.

Simulated sampling from actual or artificial populations is the only practical approach for evaluating the efficiency of a sampling method and the reliability of the associated variance estimator (Magnussen et al. 2020). However, such simulations can never fully imitate the 
actual inventory. If we use the "actual population" of direct measurements of an earlier NFI, then only subsets from the whole design can be sampled and the spatial arrangement of plots in the simulated samples will be different (sparser) than in the actual NFI. Possible artificial populations include (i) those generated as realizations from probability distributions that are designed to capture important spatial features of actual forests (e.g. Magnussen et al. 2020) and (ii) wall-to-wall maps of forest resources produced by an MS-NFI. The disadvantages of option (ii) are that MS-NFI methods tend to smooth out some of the spatial variation in the actual forests and that the correlation between the target and auxiliary variables may be smaller in MS-NFI populations consisting of spatial predictions than in actual forests. Then again, the spatial features of populations for option (ii) can resemble those of the target population of the NFI much more closely than (i), because they are based on (earlier) NFI measurements, numeric maps, and satellite images of that specific region. Another advantage of MS-NFI populations is that they can faithfully reproduce the dependencies between different target variables, in particular, if they are based on most similar neighbor or one nearest neighbor (1-nn) imputation.

The aims of this study were to compare LPM with systematic sampling and to assess the reliability of the variance estimators in a context which closely follows the sampling design phase of an operational NFI. SRS was also included in order to facilitate comparisons with other studies. The main results are based on simulated sampling from a wall-to-wall 1-nn forest resource map constructed for this study from the most recent NFI measurements. The auxiliary data for the LPM were derived from the MS-NFI of the previous inventory campaign. Such information would be available when designing a new inventory. We considered several NFI target variables, because an NFI is a multi-target inventory. The impact of using the 1-nn population as a proxy to actual forests was gauged with supplementary sampling simulations from populations of real NFI field plots, contrasting results based on the actual measurements to those based on 1-nn predictions at the same locations.

\section{Methods}

\section{Study region}

The study region covers a $60,000 \mathrm{~km}^{2}$ land area in Southern Finland (Fig. 1). It was chosen to be within one Sentinel-2 image. For the assessment of variance estimators, the region was divided into four subregions so that the area of these subregions was of the same order as that of a typical target region (province) in the Finnish NFI.

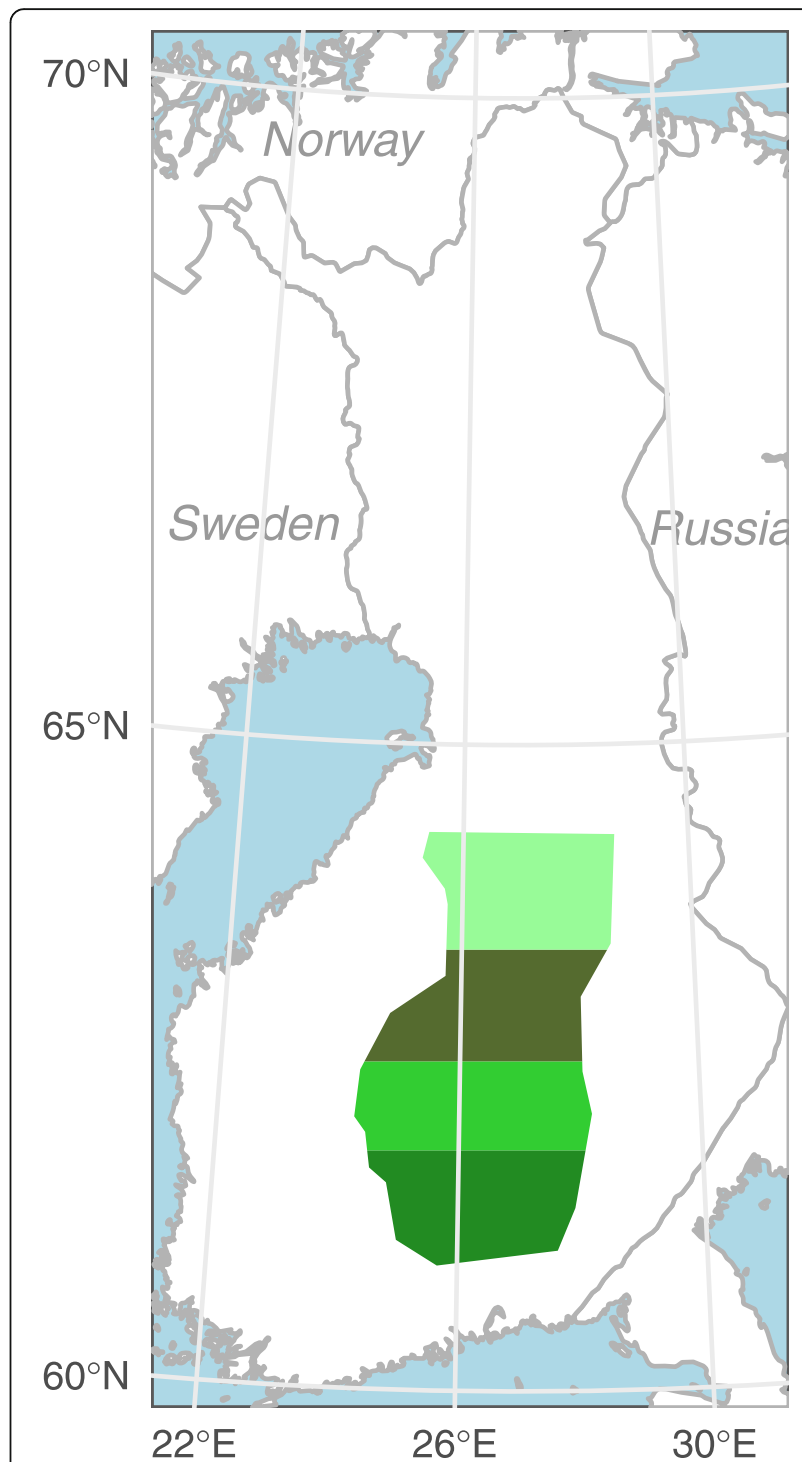

Fig. 1 Study region in Southern and Central Finland divided into four parts numbered from south to north (1-4)

\section{MS-NFI forest resource maps}

The Finnish MS-NFI of Finland has produced thematic forest resource maps over three decades. Currently the new raster maps are published biannually (http://kartta. luke.fi/index-en.html) and include themes for 44 forest variables. The MS-NFI predictions are computed using satellite data, NFI field data, map data and other digital data sources (Tomppo et al. 2008). The field data are currently computationally updated to the set date, and satellite images as close as possible to the date are used. For each pixel, a prediction is computed using the iKNN method (Tomppo and Halme 2004). The iK-NN method finds the $\mathrm{k}$ NFI field plots for each pixel where the feature vectors formed at the field plot locations are closest to the feature vector formed at the pixel 
regarding the chosen distance measure. The feature vectors include the satellite image spectral radiances, largearea mean volume estimates and other numeric data available at each pixel. The weights of the features in the distance measure are determined by a genetic algorithm. The predictions are computed as a function of the corresponding variables at the $\mathrm{k}$ nearest field plots. In this study two independent sets of MS-NFI forest resource maps were utilized. The first map was used as auxiliary data (MS-NFI-2011) and the second as target data (MSNFI-2015).

The auxiliary variables were derived from MS-NFI2011 (Tomppo et al. 2014), where the set date was July 31,2011 . To produce these maps, the value $k=5$ was used for mineral soils and peatlands and the value $k=3$ for open mires (Tomppo et al. 2014; Mäkisara et al. 2019). The satellite data was from the Landsat-5 TM images. The area used in this study included parts of several satellite images. The pixel size in the MS-NFI-2011 was 20 by $20 \mathrm{~m}$. The construction of these maps utilized the NFI field data from the years 2007-2011.

The target variables were derived from MS-NFI maps specifically produced for this research. These maps were produced using the value $k=1$ and based on the materials and methods of MS-NFI-2015 (Mäkisara et al. 2019). The choice $k=1$ was made in order to match the marginal distribution of the predictions with the distribution of the field data as well as possible (Mäkisara et al. 2019). The set date was July 31, 2015, and the satellite data were mostly OLI data from Landsat-8, but it also included some data from the MSI instrument onboard the Sentinel-2 satellite. The pixel size in the MSNFI-2015 was 16 by $16 \mathrm{~m}$. The NFI field data were collected during years 2012-2016.

\section{Field plot data}

In a supplementary study, the analyses were limited to the locations of 16,608 NFI sample plots from 1718 clusters measured within the study region during the same period as the training data of MS-NFI-2015, i.e. the years 2012-2016 (Fig. 2). The study region intersects three different NFI sampling regions. In all of them the sampling design was based on systematic cluster sampling, but the cluster configurations and cluster-to-cluster distances varied between them. Generally, the clusters and distances were smaller in the south than in the north. The distance between the sample plots in a cluster was 300 $\mathrm{m}$ in the central and northern part of the study region, while in the southernmost region it was $250 \mathrm{~m}$. The cluster dimensions varied from $1.2 \mathrm{~km} \times 1.2 \mathrm{~km}$ to 1.5 $\mathrm{km} \times 1.5 \mathrm{~km}$. The clusters were organized in five cluster groups which were replicated over the area. In this part of the study, we utilized both the NFI measurements

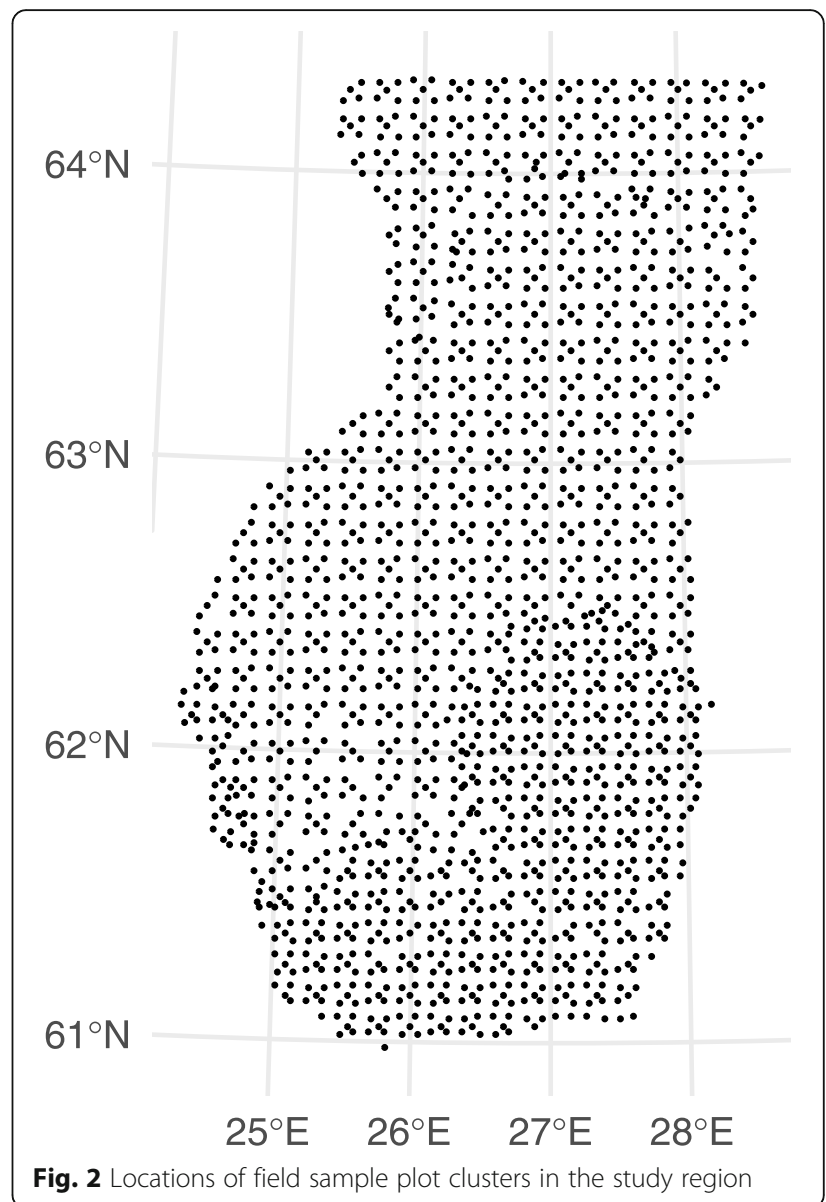

from these plots and the 1-nn predictions (MS-NFI2015) at their locations.

\section{Target populations}

Our sampling simulation aimed to imitate, the operational cluster sampling design of the Finnish NFI and some practically relevant alternatives to it. Thus, our sampling units were clusters of sample plots. To avoid unnecessary complications due to two-phase sampling (see, e.g., Grafström et al. 2017), we also defined the target populations to consist of clusters.

The field plot population of the supplementary study is already a collection of 1718 clusters. In the primary sampling simulations from the 1-nn map, we decided to mimic the NFI cluster of the southernmost part of the study region. Each cluster consisted the locations of eleven sample plot centers arranged in an L-shape with $250 \mathrm{~m}$ intervals between neighboring plots. The primary 1 -nn population was defined as a dense grid of such clusters over the study region with $50 \mathrm{~m} \times 50 \mathrm{~m}$ intervals between the corner points of neighboring clusters in the population, and the cluster-level values of the target and auxiliary variables were computed as means over the pixels containing the plot center points. 


\section{Population characteristics}

The target variables considered in this study include both growing stock characteristics and area proportions (Table 1). The tree species groups in which the growing stock volumes were estimated were spruce, pine and broadleaves. The pine group included mainly Scots pine trees (Pinus sylvestris) but also all other conifer species than Norway spruce (Picea abies). Most of the broadleaf volume consisted of birch trees (Betula pendula and Betula pubescens). Following the convention of the Finnish NFI, the estimation of stock variables was confined to the national forestry land classes: "forest land" and "poorly productive forest land" (Tomppo et al. 2011). In this study, the combination of these two classes is called "forested land"; it is close to the forest land as defined by the United Nations Food and Agriculture Organization (FAO 2012). The forested land comprised $71 \%$ of the study area and $85 \%$ of land area.

In addition to the geographic coordinates, five auxiliary variables were considered: the volume of all trees, volumes by tree species groups, and the forested land proportion of pixels in a cluster (Table 1). This set of auxiliary variables was chosen based on the experience gained in the previous studies (Räty et al. 2018; Räty and Kangas 2019). Spatial autocorrelation in the target datasets, as well as correlations between the target and auxiliary data were quite similar in the $1-\mathrm{nn}$ population and the field plot population (Fig. 3, Tables 2 and 3). Already between the closest sample plots at about 300 meters distance the spatial autocorrelation was of an order of 0.2 or less and decreasing with distance. The mean volume target variables, mean diameter, mean height, basal area, age as well as the area of mineral soils correlated strongly with the auxiliary data. The remaining area proportion variables included two rare classes with shares of $\sim 1 \%$ of the study region, namely the proportion of forests older than 140 years and open mires, which had negligible correlations with the auxiliary data. Further, the proportion of pine and spruce dominated mires had weak correlations with the auxiliary data (Tables 2 and 3 ).

\section{Sampling designs}

In the context of cluster sampling, simple random sampling (SRS) refers to selecting a completely random subset of clusters in the target population. The sample size $n$ is fixed, each set of $n$ clusters has an equal probability of being selected, and each cluster has the same probability of inclusion in the sample. No auxiliary information or predefined limitations are involved.

In systematic sampling, one random cluster is first selected from the target population and thereafter all the other sample clusters are spread over the study region at predetermined distances from each other. Hence the auxiliary information utilized in (spatially) systematic

Table 1 Population values for auxiliary and target variables in the study region in the 1-nn population and the field plot population. The target is derived from the MS-NFI-2015 map for the 1-nn population and from the NFI field measurements for the field plot population

\begin{tabular}{|c|c|c|c|c|}
\hline & & Unit & 1-nn population & Field plot population, NFI measurements \\
\hline \multirow[t]{6}{*}{ Auxiliary variable; MS-NFI-2011 } & All volume & $\mathrm{m}^{3} \cdot \mathrm{ha}^{-1}$ & 130.8 & 131.1 \\
\hline & Pine volume & $\mathrm{m}^{3} \cdot h a^{-1}$ & 55.6 & 55.6 \\
\hline & Spruce volume & $m^{3} \cdot h a^{-1}$ & 46.7 & 46.9 \\
\hline & Broadleaf volume & $\mathrm{m}^{3} \cdot \mathrm{ha}^{-1}$ & 28.5 & 28.5 \\
\hline & Forested land proportion & $\%$ & 85.6 & 82.4 \\
\hline & & & MS-NFI-2015 & NFI field \\
\hline \multirow[t]{13}{*}{ Target variable } & All volume & $\mathrm{m}^{3} \cdot h \mathrm{a}^{-1}$ & 136.0 & 136.0 \\
\hline & Pine volume & $\mathrm{m}^{3} \cdot \mathrm{ha}^{-1}$ & 56.3 & 57.2 \\
\hline & Spruce volume & $\mathrm{m}^{3} \cdot \mathrm{ha}^{-1}$ & 50.3 & 50.6 \\
\hline & Broadleaf volume & $m^{3} h a^{-1}$ & 29.7 & 28.5 \\
\hline & Age & years & 51.8 & 40.1 \\
\hline & Mean height & $d m$ & 140.0 & 140.0 \\
\hline & Mean diameter & $\mathrm{cm}$ & 16.1 & 16.0 \\
\hline & Basal area & $\mathrm{m}^{2} \cdot \mathrm{ha}^{-1}$ & 17.4 & 17.4 \\
\hline & Age $140+$ yrs. & $\%$ & 1.4 & 0.7 \\
\hline & Mineral soils & $\%$ & 63.3 & 60.8 \\
\hline & Spruce mire & $\%$ & 8.8 & 9.1 \\
\hline & Pine mire & $\%$ & 13.5 & 12.9 \\
\hline & Open mire & $\%$ & 1.2 & 1.4 \\
\hline
\end{tabular}




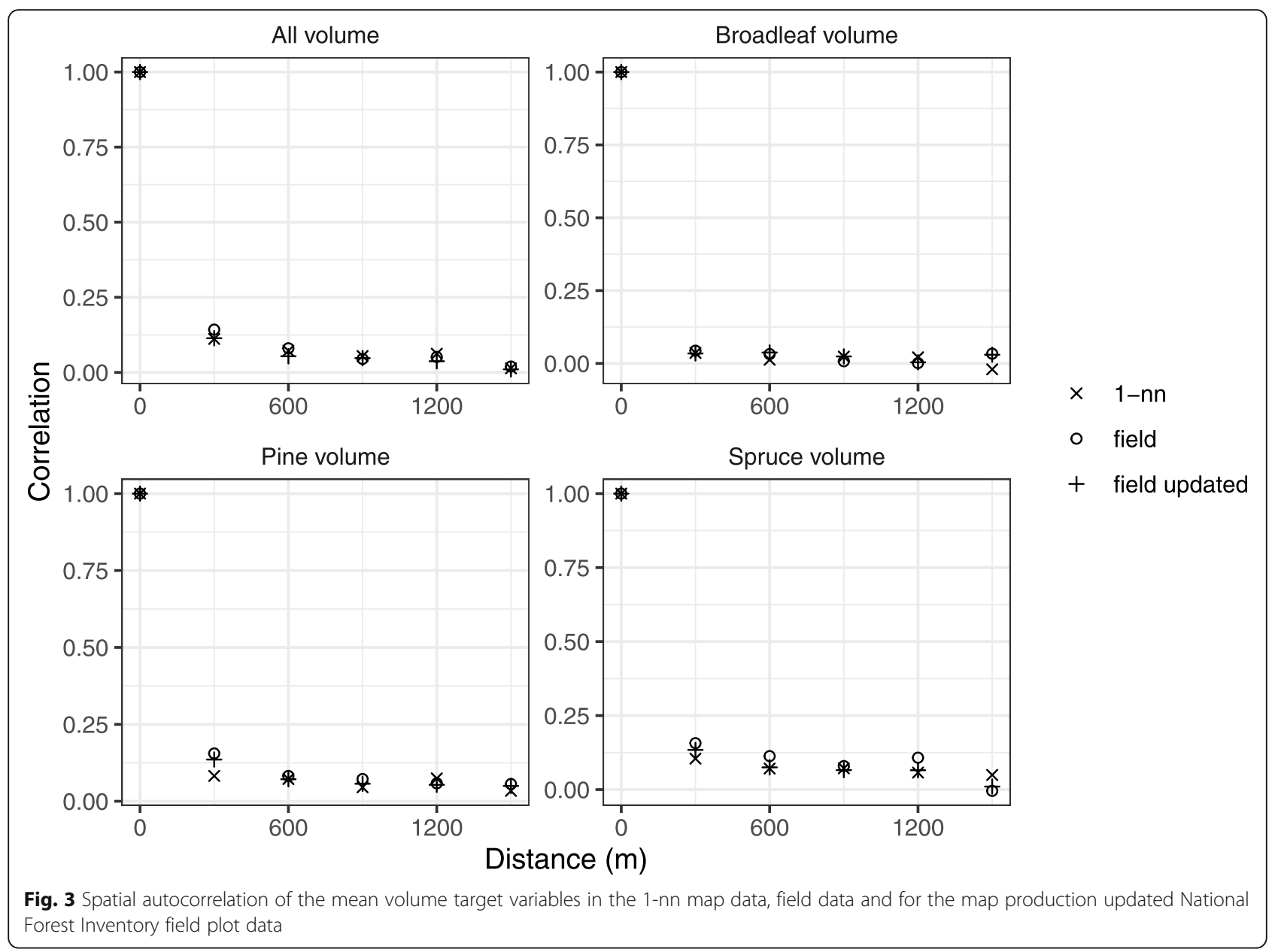

sampling are the geographic cluster coordinates. In our systematic sampling design, a systematic square grid of clusters was selected at $6 \mathrm{~km}$ intervals, yielding a sample size of $n=1,678$ clusters on average.

The local pivotal method (LPM, Grafström et al. 2012, 2017) aims at samples where the empirical distributions of auxiliary variables are similar to the corresponding population distributions. This is implemented by promoting one unit in the sample selection at the expense of the unit closest to it in the auxiliary variable space. The closeness of population units $i$ and $j$ are measured by the Euclidean distance metric between the units' standardized auxiliary variables.

In LPM, an iterative selection algorithm is used to select the sample. We used equal-probability sampling giving a fixed inclusion probability for each observation. In the iterative algorithm, these initially non-zero inclusion probabilities are first assigned to all population units and later they are updated and act as inclusion indicators. In each selection round one population unit, the state of which is not yet determined (i.e., the unit is neither excluded nor included to the sample), is randomly chosen and its closest unit in the group of units with an undetermined state is found. The two units $i$ and $j$ are then compared, and their inclusion indicators updated according to the equation:

$$
\left(\pi_{i}, \pi_{j}{ }^{\prime}\right)=\left\{\begin{array}{l}
(a, b) \text { with probability }\left(a-\pi_{j}\right) /\left(a-\pi_{j}\right) \\
(b, a) \text { with probability }\left(a-\pi_{j}\right) /\left(a-\pi_{j}\right)
\end{array}\right.
$$

where $a=\min \left(1, \pi_{i}+\pi_{j}\right)$ and $b=\pi_{i}+\pi_{j}-a$. As a result, at least one of them is either included in the sample, if its inclusion indicator becomes 1 , or excluded if its inclusion indicator is 0 . At the end of the selection algorithm all population units are in a determined state. We considered six different LPM designs, i.e., combinations of the auxiliary variables (Table 4).

In the SRS and LPM the sample size was matched to the same density per land area as in the systematic design. The total number of all possible different samples for the systematic design was $(6,000 \mathrm{~m} / 50 \mathrm{~m})^{2}=14,400$. Results were calculated for each of these. The total 
Table 2 Cluster-level correlations between each auxiliary variable with the other auxiliary variables and the target variables in the $1-\mathrm{nn}$ population study

\begin{tabular}{|c|c|c|c|c|c|c|}
\hline & & \multicolumn{5}{|c|}{ Auxiliary data, MS-NFI-2011 } \\
\hline & & All volume & Pine volume & Spruce volume & Broadleaf volume & $\begin{array}{l}\text { Forested land } \\
\text { proportion }\end{array}$ \\
\hline \multirow[t]{5}{*}{ Auxiliary data; MS-NFI-2011 } & All volume & 1.00 & 0.70 & 0.80 & 0.66 & 0.80 \\
\hline & Pine volume & 0.70 & 1.00 & 0.20 & 0.22 & 0.72 \\
\hline & Spruce volume & 0.80 & 0.20 & 1.00 & 0.48 & 0.45 \\
\hline & Broadleaf volume & 0.66 & 0.22 & 0.48 & 1.00 & 0.60 \\
\hline & Forested land proportion & 0.80 & 0.72 & 0.45 & 0.60 & 1.00 \\
\hline \multirow[t]{13}{*}{ Target data; MS-NFI-2015 } & All volume & 0.81 & 0.56 & 0.65 & 0.56 & 0.71 \\
\hline & Pine volume & 0.57 & 0.74 & 0.21 & 0.22 & 0.63 \\
\hline & Spruce volume & 0.61 & 0.18 & 0.72 & 0.42 & 0.38 \\
\hline & Broadleaf volume & 0.40 & 0.17 & 0.29 & 0.57 & 0.44 \\
\hline & Age & 0.69 & 0.73 & 0.35 & 0.39 & 0.81 \\
\hline & Mean height & 0.84 & 0.70 & 0.57 & 0.57 & 0.84 \\
\hline & Mean diameter & 0.83 & 0.71 & 0.55 & 0.54 & 0.83 \\
\hline & Basal area & 0.83 & 0.67 & 0.58 & 0.57 & 0.83 \\
\hline & Age $140+$ yrs. & 0.10 & 0.16 & 0.02 & 0.00 & 0.13 \\
\hline & Mineral soils & 0.74 & 0.49 & 0.59 & 0.56 & 0.73 \\
\hline & Spruce mire & 0.25 & 0.18 & 0.14 & 0.27 & 0.34 \\
\hline & Pine mire & 0.07 & 0.39 & -0.24 & -0.02 & 0.37 \\
\hline & Open mire & -0.10 & 0.00 & -0.13 & -0.09 & -0.00 \\
\hline
\end{tabular}

Table 3 Cluster-level correlations between each cluster-level auxiliary variable and the other auxiliary variables in the data itself and the auxiliary data and the target variables in the field plot data study

\begin{tabular}{|c|c|c|c|c|c|c|}
\hline & & \multicolumn{5}{|c|}{ Auxiliary data, MS-NFI-2011 } \\
\hline & & All volume & Pine volume & Spruce volume & Broadleaf volume & $\begin{array}{l}\text { Forested land } \\
\text { proportion }\end{array}$ \\
\hline \multirow[t]{5}{*}{ Auxiliary data; MS-NFI-2011 } & All volume & 1.00 & 0.72 & 0.80 & 0.65 & 0.81 \\
\hline & Pine volume & 0.72 & 1.00 & 0.23 & 0.23 & 0.72 \\
\hline & Spruce volume & 0.80 & 0.23 & 1.00 & 0.47 & 0.48 \\
\hline & Broadleaf volume & 0.65 & 0.23 & 0.47 & 1.00 & 0.60 \\
\hline & Forested land proportion & 0.81 & 0.72 & 0.48 & 0.60 & 1.00 \\
\hline \multirow[t]{13}{*}{ Target data; NFI field data } & All volume & 0.82 & 0.57 & 0.67 & 0.53 & 0.69 \\
\hline & Pine volume & 0.53 & 0.76 & 0.15 & 0.17 & 0.56 \\
\hline & Spruce volume & 0.61 & 0.14 & 0.76 & 0.41 & 0.39 \\
\hline & Broadleaf volume & 0.41 & 0.15 & 0.32 & 0.58 & 0.40 \\
\hline & Age & 0.69 & 0.71 & 0.39 & 0.35 & 0.73 \\
\hline & Mean height & 0.84 & 0.69 & 0.58 & 0.56 & 0.81 \\
\hline & Mean diameter & 0.83 & 0.69 & 0.58 & 0.53 & 0.80 \\
\hline & Basal area & 0.82 & 0.64 & 0.59 & 0.56 & 0.79 \\
\hline & Age $140+$ yrs. & 0.08 & 0.11 & 0.05 & 0.00 & 0.07 \\
\hline & Mineral soils & 0.72 & 0.48 & 0.58 & 0.54 & 0.72 \\
\hline & Spruce mire & 0.31 & 0.21 & 0.20 & 0.31 & 0.39 \\
\hline & Pine mire & 0.07 & 0.38 & -0.22 & -0.05 & 0.33 \\
\hline & Open mire & -0.13 & -0.03 & -0.15 & -0.11 & -0.02 \\
\hline
\end{tabular}


number of samples drawn by the SRS and all the LPM designs was at least 56,700 .

The supplementary sampling simulations from the field plot population were carried out with a set-up similar to Räty et al. (2018). The sample size in these simulations was 130 clusters. This set-up enabled a comparison of only the SRS and LPM sampling methods. Because the initial NFI population was already a sparse systematic design selecting an even sparser systematic design from it was out of the question. Each sampling design was replicated 100,000 times and results were calculated for each of them.

\section{Evaluation of sampling designs and variance estimators}

As a result of the sampling simulations, we thus obtained $T$ samples of clusters from the target populations with each of the sampling methods. Let $S_{t}, t \in 1,2, \ldots, T$ be the set of clusters included in the $t^{\prime}$ th sample by one of the methods. Following the convention of the Finnish NFI, both the growing stock characteristics and area proportions were estimated from each sample using ratio estimators of the general form

$$
\hat{\mu}_{t}=\frac{\sum_{i \in S_{t}} y_{i}}{\sum_{i \in S_{t}} x_{i}}
$$

in which the target $\mu$ was an area proportion, $y_{i}$ was the number of those plots of cluster $i$ that belong to the target land class (old-growth forests, mineral soils, or different types of mires; see Table 1 ) and $x_{i}$ represented the number of land plots in that cluster. In the case of growing stock characteristics, $y_{i}$ was the sum of their plotlevel values over the forested land plots of cluster $i$ and $x_{i}$ was the number of forested land plots.

The comparison of the sampling designs was based on the mean squared errors (MSE):

$$
\mathrm{MSE}=\frac{1}{T} \sum_{t=1}^{T}\left(\hat{\mu}_{t}-\mu\right)^{2}
$$

where $\mu$ is the value of the target parameter computed from the entire target population (see Table 1). Relative efficiencies (REs) were estimated as ratios between the MSEs (Eq. 3) associated with the different sampling designs: the MSE of the reference sampling design, $\mathrm{MSE}_{r e f}$, was divided by the MSE of an alternative sampling design, $\mathrm{MSE}_{i}$ :

$$
\mathrm{RE}_{i}=\frac{\mathrm{MSE}_{r e f}}{\mathrm{MSE}_{i}}
$$

Consequently, $\mathrm{RE}_{i}>1$ identified the designs that were more efficient (i.e., with a smaller MSE) than the reference sampling design.

The empirical variance over the replications,

$$
V_{\text {sim }}(\hat{\mu})=\frac{1}{T} \sum_{t=1}^{T}\left(\hat{\mu}_{t}-M\right)^{2}
$$

where $M=\frac{1}{T} \sum_{t=1}^{T} \hat{\mu}_{t}$, served as the benchmark, when assessing the performance of various estimators of sampling variance based on single samples. The conventional (SRS) variance estimator for the ratio estimator of Eq. (1) is (e.g. Cochran 1977, sec. 6.3)

$$
\hat{V}_{\text {srs }}\left(\hat{\mu}_{t}\right)=\frac{\sum_{i \in S_{t}}\left(y_{i}-\hat{\mu}_{t} x_{i}\right)^{2}}{\left(\sum_{i \in S_{t}} \mathbf{x}_{i}\right)^{2}}
$$

Local difference estimators, including the approximate variance estimator proposed for the LPM by Grafström and Schelin (2014), essentially replace the squared sum of global residuals $z_{i}=y_{i}-\hat{\mu}_{t} x_{i}$ in the numerator of Eq. (6) with a squared sum of local differences of $z_{i}$ 's. For the ratio estimators, the general form of the GrafströmSchelin estimator is modified into:

$$
\hat{V}_{\mathrm{sb}}\left(\hat{\mu}_{t}\right)=\frac{1}{\left(\sum_{i \in S_{t}} x_{i}\right)^{2}} \sum_{i \in S_{t}} \frac{n_{i}^{*}}{n_{i}^{*}-1}\left(z_{i}-\frac{1}{n_{i}^{*}} \sum_{j \in S_{t, i}^{*}} z_{j}\right)^{2}
$$

where $S_{t, i}^{*}$ is a subset of $S_{t}$ including cluster $i$ and its closest neighbors in the space of auxiliary variables and $n_{i}^{*}$ is the number of clusters in $S_{t, i}^{*}$.

For the LPM samples, we used the version of $\hat{V}_{\mathrm{sb}}\left(\hat{\mu}_{t}\right)$, where $S_{t, i}^{*}$ consisted of cluster $i$ and its one closest neighbor $j^{\prime \prime}(i) \in S_{t}$. In that case, Eq. (7) simplified into:

$$
\hat{V}_{\mathrm{sb}}\left(\hat{\mu}_{t}\right)=\frac{1}{2\left(\sum_{i \in S_{t}} x_{i}\right)^{2}} \sum_{i \in S_{t}}\left(z_{i}-z_{j^{*}(i)}\right)^{2}
$$

(c.f. Grafström and Schelin 2014, eq. 8). For systematic samples, $S_{t, i}^{*}$ contained cluster $i$ and all its nearest geographic neighbors so that $n_{i}^{*}=5$ for "interior" clusters $i$ and $n_{i}^{*}<5$ for the edge clusters.

From systematic samples, we also computed the variance estimates by Matérn (1947).

$$
\hat{V}_{\text {Mat }}\left(\hat{\mu}_{t}\right)=\frac{1}{4\left(\sum_{i \in S_{t}} x_{i}\right)^{2}} \sum_{g}\left(z_{g_{1}}-z_{g_{2}}-z_{g_{3}}+z_{g_{4}}\right)^{2}
$$

where the sum extends over all groups $g$ of four neighboring clusters of the square grid so that at least one point in the group belongs to the sample $S_{t}$. The $z$-values corresponding to grid points outside the study region were set to 0 (c.f. Matérn 1960, sec 6.7).

Reliability of variance estimators of Eqs. (6), (7), (8), (9) were assessed by comparing the averages of the 


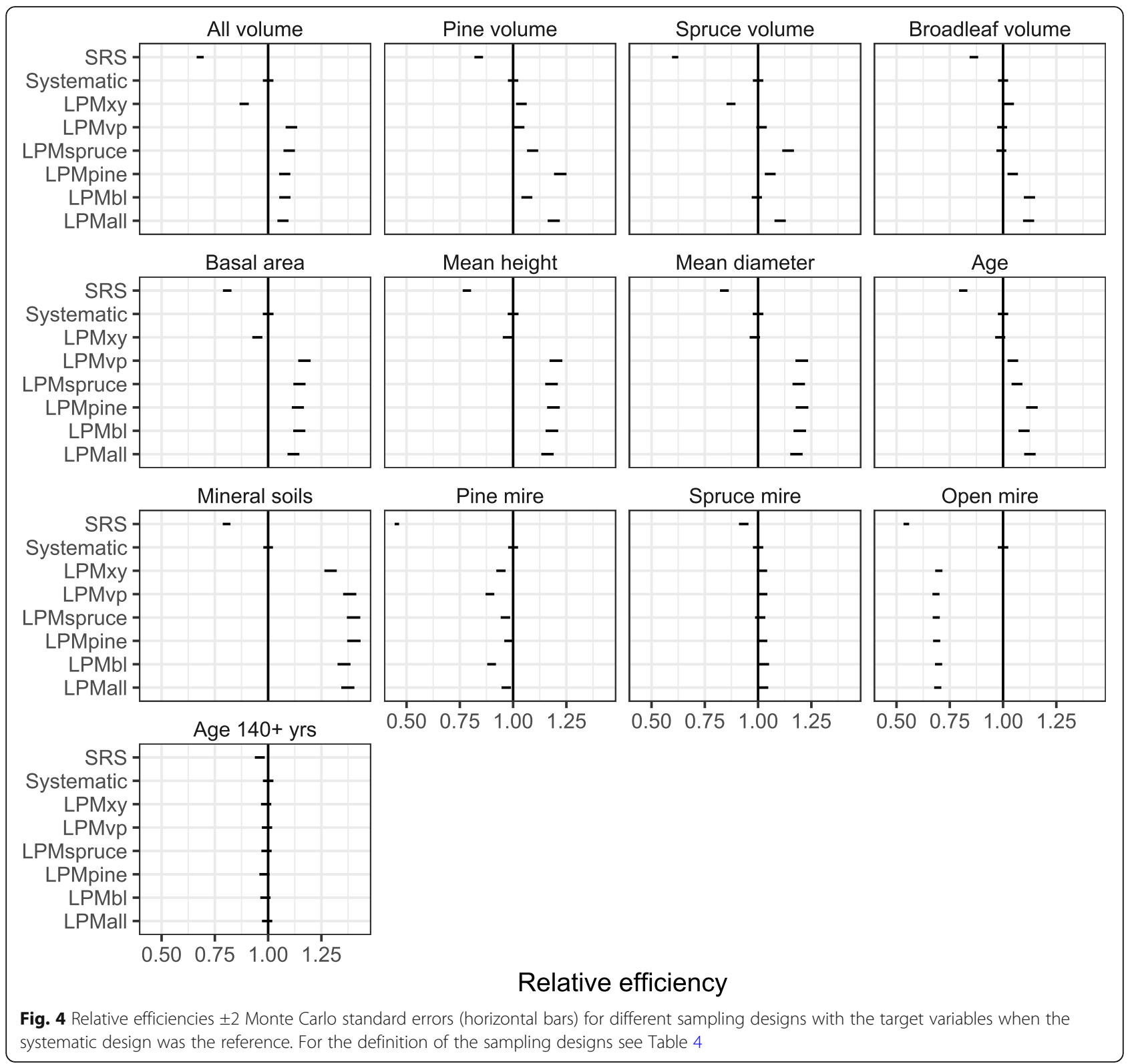

single sample estimates $\hat{V}_{\text {srs }}\left(\hat{\mu}_{t}\right), \hat{V}_{\mathrm{sb}}\left(\hat{\mu}_{t}\right)$, and $\hat{V}_{\text {Mat }}\left(\hat{\mu}_{t}\right)$ over the replications $t$ to the benchmark $V_{\text {sim }}(\hat{\mu})$.

The Monte Carlo error of the variance estimators was estimated using the formula for the standard error of the mean:

$$
\text { s.e. }(\hat{V}(\hat{\mu}))=\sqrt{\frac{1}{T}} \sqrt{\frac{1}{T} \sum_{t=1}^{T}\left(\hat{V}\left(\hat{\mu}_{t^{\prime}}\right)-\frac{1}{T} \sum_{t=1}^{T} \hat{V}\left(\hat{\mu}_{t^{\prime}}\right)\right)^{2}}
$$

For the empirical variance we used the formula (Rao 1973):

where $M_{k}=\frac{1}{T} \sum_{t=1}^{T}\left(\mu_{t}-M_{1}\right)^{k}$ for $k=2,4$ and $M_{1}$ $=\frac{1}{T} \sum_{t=1}^{T} \mu_{t}$.

All the simulations of the two studies were performed with freely available open software R ( R Core Team 2018) and Julia (Bezanson et al. 2017). The function used to perform the LPM was 'lpm2_kdtree' of the $\mathrm{R}$ package 'SamplingBigData' (Lisic and Grafström 2018). 


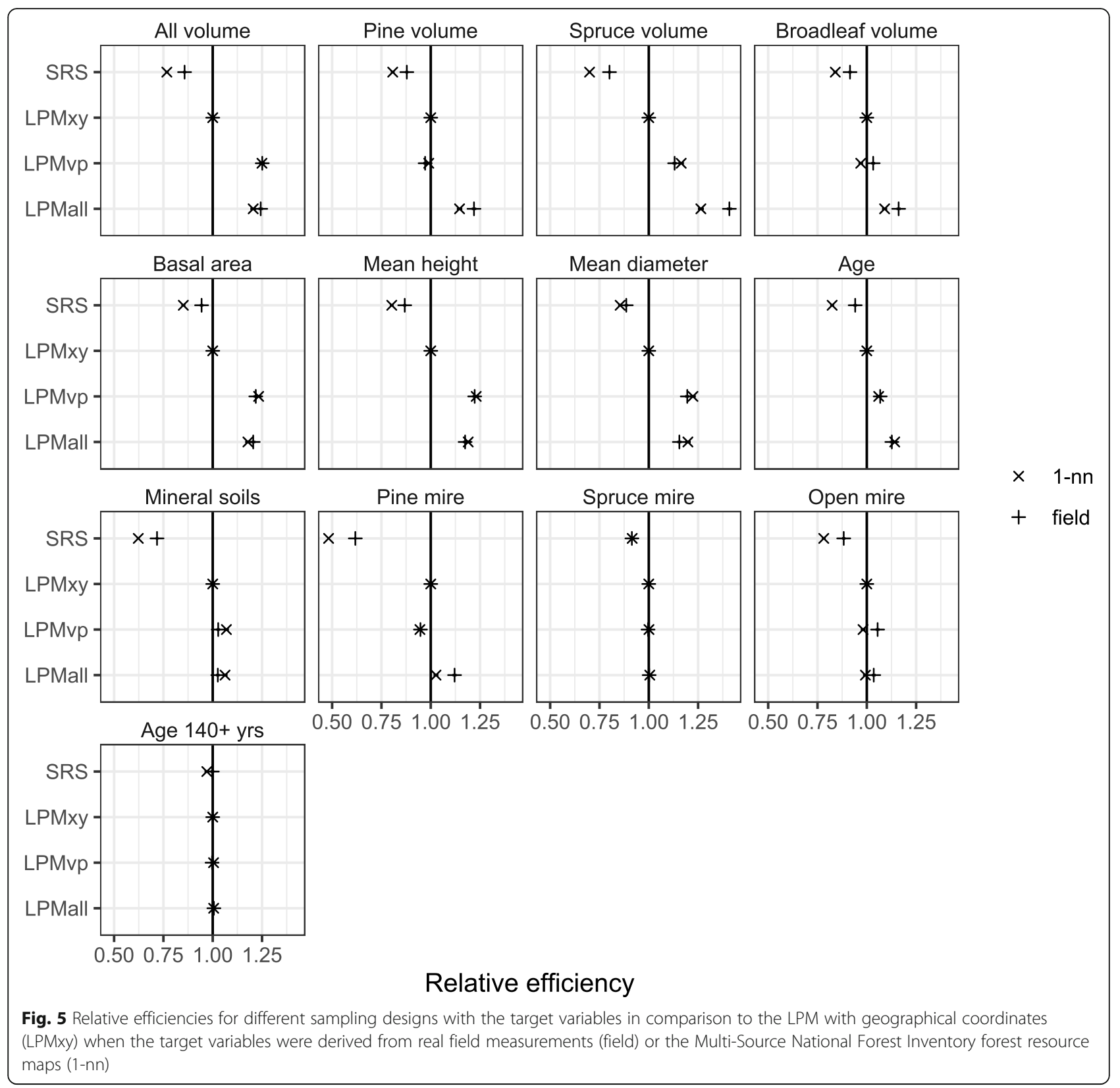

\section{Results}

\section{Comparison of sampling designs}

The MSEs of the target variable estimates for the whole 1-nn population were calculated over all repetitions defined in section sampling designs (Table 5). The means of the target variables coincided with the population values in Table 1 and the estimates were approximately normally distributed around the means.

The REs of SRS for single target variables varied between 0.5 and 1.0 in comparison to the systematic design (Fig. 4). The mean RE of SRS was 0.77.

When considered over all target variables, the mean RE of LPMxy was close to the systematic method and was 0.97 . The other LPM designs resulted in slightly larger overall REs than the systematic method on average. However, the differences between the different LPM designs were small: the mean REs varied between 1.06 and 1.09. In addition, the Monte Carlo error associated with the target variable estimation was negligible (Fig. 4).

Examining the results with the all target variables separately, the most efficient sampling design and its efficiency varied (Fig. 4). For the mean volume of all tree species, all the LPM designs including some information on the forest resources had REs close to 1.1. For tree-species-specific mean volumes the largest enhancements were gained with the LPM designs 


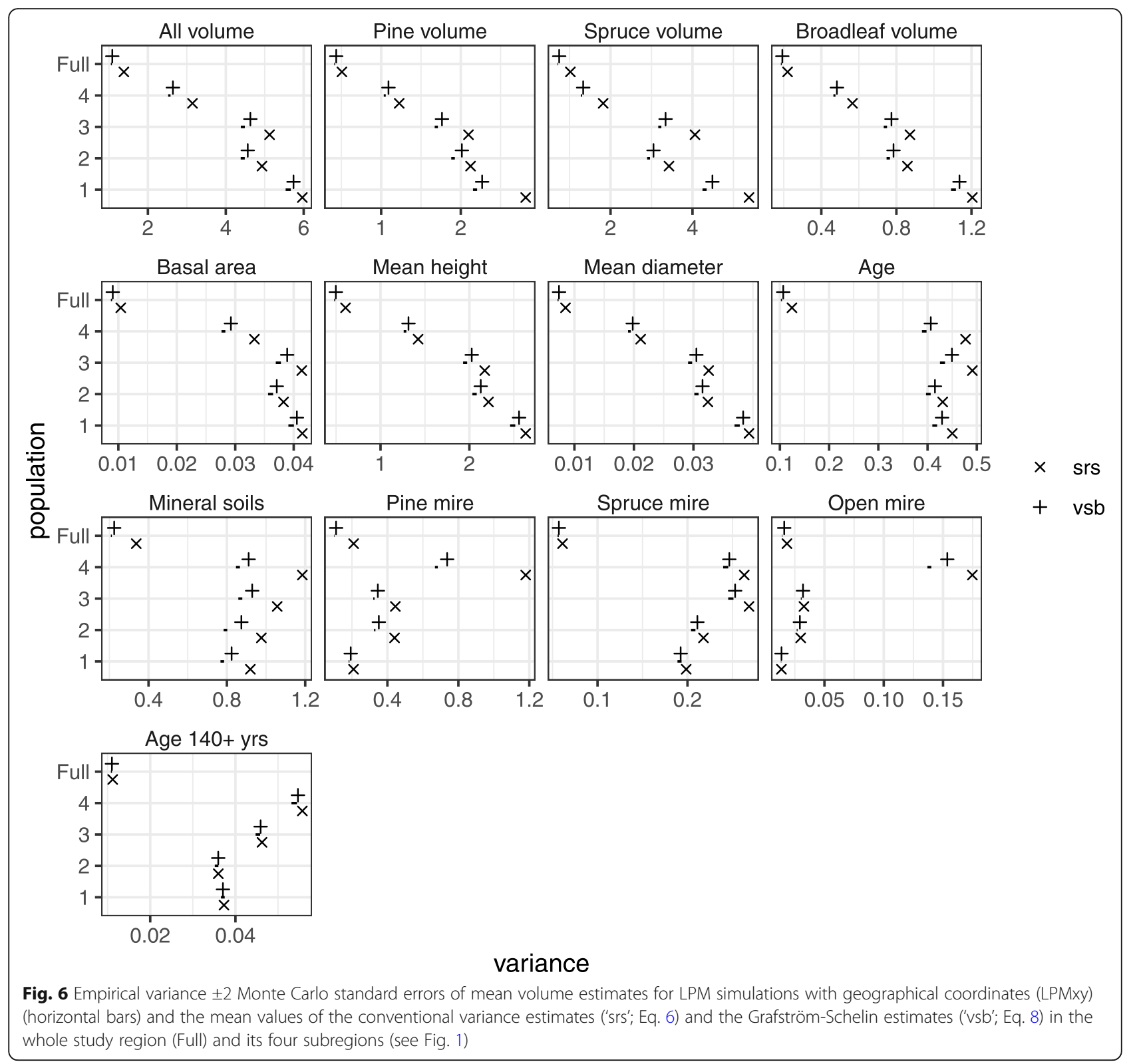

which included auxiliary information on that specific tree species. The maximum REs reached for the mean spruce and broadleaves volume were $\sim 1.1$ and for the mean pine volumes $\sim 1.2$.

For the variables associated and generally known to correlate with volume, namely the mean diameter, mean height, age and BA, the REs of the LPM designs (other than LPMxy) were between 1.0-1.2. For the main site type class variables, the results differed (Fig. 4, third row): For the class of mineral soils, which encloses the most productive forests, the LPM designs had larger REs than for the poorly productive mires. Further, all the LPM designs including LPMxy were poor for the treeless open mires. In estimations of the area proportion of old forests aged over 140 years all the sampling designs had the same efficiency.

\section{Supplementary field data study}

When the population was limited to the field sample plot locations and the efficiencies were estimated against LPMxy, in all cases SRS was the least efficient sampling method (Fig. 5). Enhancements at individual target variable level were from 1.2 to 1.4 for the mean volume and stand variables for the LPM designs. For the land class variables all REs were less than 1.2. The REs were typically a bit larger for the target variables derived from the real field data than for the targets derived from the MS-NFI-2015 maps. 


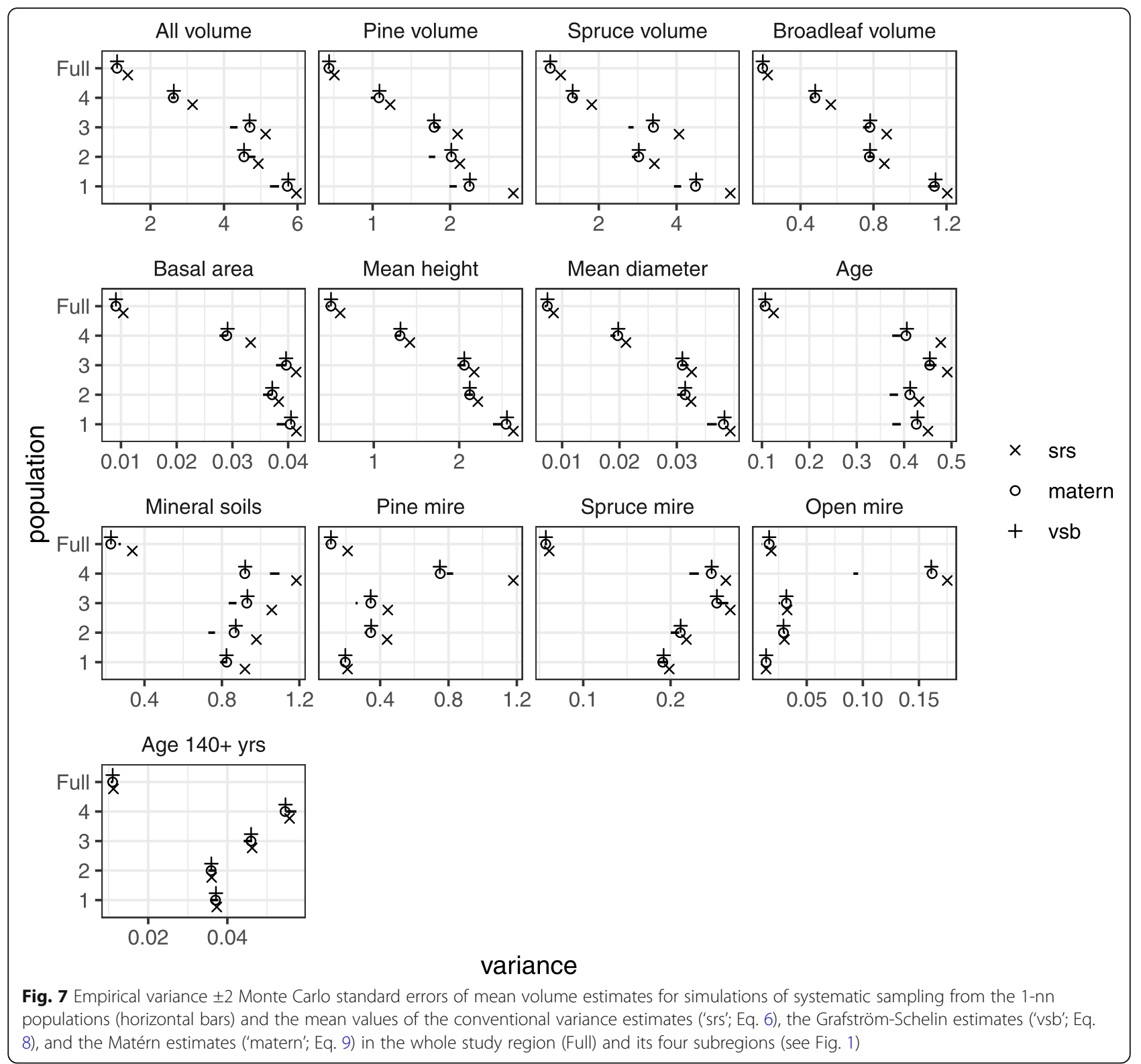

\section{Reliability of variance estimators}

In simulations of LPMxy, averages of both the Grafström-Schelin estimates $\hat{V}_{\mathrm{sb}}$ and conventional variance estimates $\hat{V}_{\text {srs }}$ were never smaller than the empirical variance over the replicated samples, $V_{\text {sim }}(\hat{\mu})$. Taking into account the Monte Carlo error of $V_{\text {sim }}(\hat{\mu})$, both $\hat{V}_{\text {srs }}$ and $\hat{V}_{\text {sb }}$ were significant overestimates in most cases, but $\hat{V}_{\text {sb }}$ much less so (Fig. 6). The average deviation from the empirical variance was $7.2 \%$ for $\hat{V}_{\mathrm{sb}}$ and 24\% for $V_{\text {sim }}$ (Additional file 1: Table S1).

In the simulations of systematic sampling, the averages of the $\hat{V}_{\mathrm{sb}}\left(\hat{\mu}_{t}\right)$ and the Matérn estimates $\hat{V}_{\text {Mat }}\left(\hat{\mu}_{t}\right)$ over the replications $t$ were practically identical to each other (Fig. 7). The most common result was that they overestimated the empirical variance (they were significantly greater than $\left.V_{\text {sim }}(\hat{\mu})\right)$, but less so than $\hat{V}_{\text {srs }}$. However, we also observed underestimation in some cases, most notably for the area of mineral soils in subpopulation 4.

In LPM simulations utilizing other auxiliary variables in addition to the coordinates, $\hat{V}_{\text {sb }}$ underestimated the sampling variance in several cases. For example, when all auxiliary variables were used in LPM, significant underestimation occurred in almost all the subpopulation results (Fig. 8). For the whole population, the Monte Carlo error of $V_{\text {sim }}$ was always so small that the error bar ostensibly reduced into a point (Fig. 8), and $\hat{V}_{\mathrm{sb}}$ agreed with it so well that the points are hardly visible. 


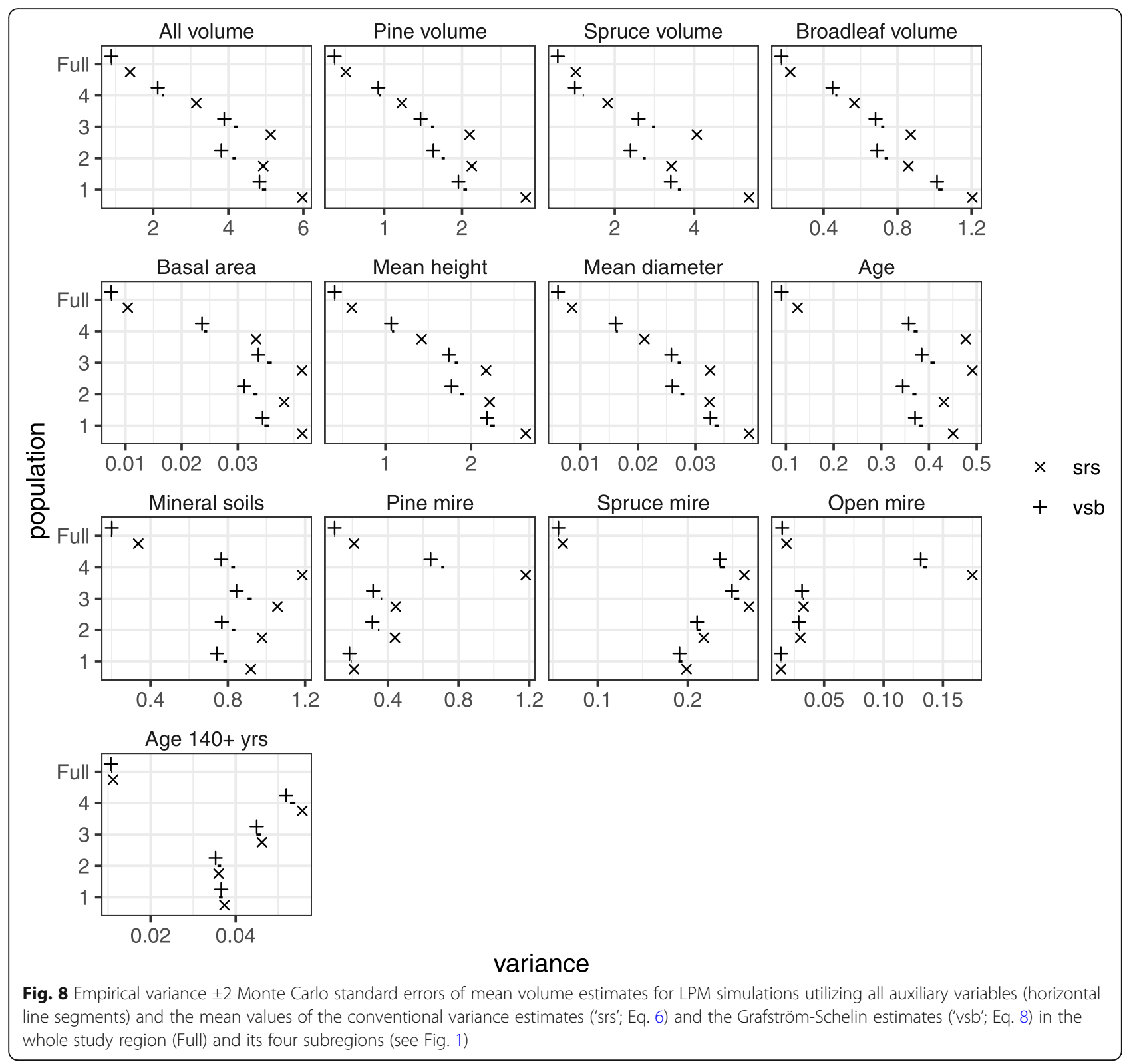

\section{Discussion}

To the best of our knowledge, this is the first study that has compared LPM with systematic sampling in NFI. In previous studies (Grafström and Ringvall 2013; Grafström and Schelin 2014; Grafström et al. 2017; Räty et al. 2018), SRS or LPMxy has been used as the reference when assessing the efficiency of LPM with additional auxiliary variables. We found that for some target variables, LPMxy was markedly less efficient than systematic sampling. This is one reason why our observed REs of LPM designs that are relative to the systematic design were smaller than the REs in previous works relative to SRS or LPMxy.

Several studies have observed enhancements in the estimation efficiency when LPM has utilized auxiliary data correlating with the target variables in addition to the geographic coordinates, (e.g. Grafström and Ringvall 2013; Roberge et al. 2017; Grafström and Matei 2018; Räty et al. 2018). As in Grafström and Ringvall (2013), also in our data, the correlations which we used to explore the explanatory power between the auxiliary and target variables were strong between the mean volume related target and auxiliary data (Tables 4-5). However, compared to the previous studies the improvements in estimation efficiency were modest. In the previous studies (Grafström and Ringvall 2013; Roberge et al. 2017; Räty et al. 2018), the REs were on the level of 1.5-3 relative to LPMxy and 1.1-7.5 relative to SRS depending on the target variable. In our study the overall REs of all designs 
Table 4 Combinations of cluster-level auxiliary variables utilized with the LPM designs. The ' + ' sign indicates the variables included to the design

\begin{tabular}{|c|c|c|c|c|c|c|c|}
\hline \multirow{2}{*}{$\begin{array}{l}\text { Sampling } \\
\text { design }\end{array}$} & \multicolumn{2}{|c|}{ Coordinates } & \multirow{2}{*}{$\begin{array}{l}\text { All } \\
\text { volume }\end{array}$} & \multirow{2}{*}{$\begin{array}{l}\text { Pine } \\
\text { volume }\end{array}$} & \multirow{2}{*}{$\begin{array}{l}\text { Spruce } \\
\text { volume }\end{array}$} & \multirow{2}{*}{$\begin{array}{l}\text { Broadleaf } \\
\text { volume }\end{array}$} & \multirow{2}{*}{$\begin{array}{l}\text { Forested land } \\
\text { proportion }\end{array}$} \\
\hline & $x$ & $Y$ & & & & & \\
\hline LPMxy & + & + & & & & & \\
\hline LPMvp & + & + & + & & & & + \\
\hline LPMspruce & + & + & + & & + & & + \\
\hline LPMpine & + & + & + & + & & & + \\
\hline LPMbl & + & + & + & & & + & + \\
\hline LPMall & + & + & + & + & + & + & + \\
\hline
\end{tabular}

were markedly smaller, $1.07-1.11$ compared to LPMxy and 1.3-1.45 compared to SRS.

Our 1-nn target population was a map based on modelling, which adds uncertainty to the pixels in the target maps (Magnussen et al. 2009) compared to earlier studies where, for example, the target has been inventory field data (Räty et al. 2018). In addition, the spatial pattern might be different in the maps than in reality. We gauged the impacts of such deviations from directly observed forest variables in a supplementary study, in which both field observations and 1-nn predictions were available to all population units. The REs of LPM with additional variables vs. LPMxy were larger with the field data than with the map and these larger REs were in line with the previous study by Räty et al. (2018). This implies that the above-mentioned map uncertainty or the spatial differences had some impact on the results. However, the differences were small (Fig. 4).

NFI is a multi-target inventory, which places demands on the considered sampling methods. Therefore, the LPM should also be examined using several variables. In the previous studies the efficiencies have been studied mostly with variables related to the growing stock (Grafström et al. 2017; Räty et al. 2018). One could argue that this is not enough because NFIs deal with dozens if not hundreds of variables (Tomppo et al. 2010; Vidal et al. 2016) and not all of them correlate with the chosen auxiliary variables. For continuous variables, for instance, the mean diameter, mean height, age, and basal area, which are known to correlate with the auxiliary data (volumes), the REs were similar to those for the mean volume of all tree species when compared to the systematic design. Additionally, the area estimates for the main site type classes, which correlated with the auxiliary data, improved with LPM even though more modest REs were detected. On the other hand, if the target variable was a rare and uncorrelated phenomenon, there were two possible outcomes: 1) in the area proportion estimation of old forests, all the sampling methods were equal; and 2) in the area proportion estimation of the open mires, all LPM designs were significantly less efficient than the systematic design (Fig. 4). In the first case, the variable was visually observed to be evenly spread

Table 5 The mean squared errors (MSEs) of the target variable estimates from the simulation replications

\begin{tabular}{|c|c|c|c|c|c|c|c|c|}
\hline Variable & LPMxy & LPMvp & LPMspruce & LPMpine & LPMbl & LPMall & SRS & Systematic \\
\hline All volume $\left(\mathrm{m}^{2} \cdot h \mathrm{~h}^{-1}\right)$ & 0.94 & 1.38 & 1.06 & 0.85 & 0.86 & 0.87 & 0.87 & 0.88 \\
\hline Pine volume $\left(\mathrm{m}^{2} \cdot \mathrm{ha}^{-1}\right)$ & 0.43 & 0.51 & 0.41 & 0.42 & 0.39 & 0.35 & 0.40 & 0.36 \\
\hline Spruce volume $\left(\mathrm{m}^{2} \cdot \mathrm{ha}^{-1}\right)$ & 0.62 & 1.02 & 0.71 & 0.61 & 0.55 & 0.59 & 0.63 & 0.57 \\
\hline Broadleaf volume $\left(\mathrm{m}^{2} \cdot \mathrm{ha}^{-1}\right)$ & 0.19 & 0.22 & 0.19 & 0.19 & 0.19 & 0.18 & 0.17 & 0.17 \\
\hline Age (years) & 0.10 & 0.13 & 0.10 & 0.10 & 0.10 & 0.09 & 0.09 & 0.09 \\
\hline Mean height $(\mathrm{dm})$ & 0.47 & 0.60 & 0.48 & 0.39 & 0.40 & 0.40 & 0.40 & 0.41 \\
\hline Mean diameter $\left(10^{-3} \mathrm{~cm}\right)$ & 7.14 & 8.48 & 7.25 & 5.92 & 5.99 & 5.92 & 5.97 & 6.05 \\
\hline Basal area $\left(10^{-3} \mathrm{~m}^{2} \cdot \mathrm{ha}^{-1}\right)$ & 8.38 & 10.37 & 8.83 & 7.16 & 7.31 & 7.35 & 7.31 & 7.49 \\
\hline Age $140+$ yrs. $\left(10^{-2} \%\right)$ & 1.08 & 1.12 & 1.09 & 1.09 & 1.09 & 1.10 & 1.09 & 1.08 \\
\hline Mineral soils (\%) & 0.27 & 0.34 & 0.21 & 0.20 & 0.19 & 0.19 & 0.20 & 0.20 \\
\hline Spruce mire $\left(10^{-2} \%\right)$ & 5.73 & 6.14 & 5.62 & 5.62 & 5.67 & 5.62 & 5.58 & 5.60 \\
\hline Pine mire $\left(10^{-1} \%\right)$ & 0.95 & 2.10 & 1.01 & 1.07 & 0.99 & 0.97 & 1.06 & 0.99 \\
\hline Open mire $\left(10^{-2} \%\right)$ & 1.01 & 1.85 & 1.44 & 1.47 & 1.47 & 1.47 & 1.45 & 1.46 \\
\hline
\end{tabular}


over the study region and, in the second case, oppositely, the open mires were spatially clustered and more concentrated in the northern part of the study region. Hence, we conclude that efficiency of LPM depends on the chosen auxiliary and target variables and their spatial pattern. Thus, caution should be retained if applied in the NFI for many target variables.

Another concern, when applying LPM in practice, is that gaps or areas of more sparsely placed sample plots in the middle of the inventory region are possible even though the geographical spread is also used besides the other auxiliary data. The NFI results are estimated in many different spatial scales which such gaps may affect. Even though NFIs were originally designed for largescale estimation, the demand for reporting results for smaller and smaller areal units is growing. In Finland, based on the field sample plots the inventory result estimation is solely possible for $3000-5000 \mathrm{~km}^{2}$ with the current systematic design (Tomppo et al. 2008), but by combining remotely sensed and other spatial data results can be calculated for municipalities with areas from 6 $\mathrm{km}^{2}$ upwards. With the systematic design approach there is no risk of gaps, which may be regarded as its advantage over the LPM.

This and previous studies (e.g. Grafström et al. 2017; Räty et al. 2018) have been based on simulating a sample selection with different sampling methods and designs. However, we observed that the response depended both on the target variable and target dataset. In the 1-nn population the average distance between the clusters was markedly smaller than in the field plot population, which gives another explanation to the differences on the observed levels of the REs in the different study setups. In fact, if in the 1-nn-population we would have sampled using the same average distance as in the field plot population, we would have obtained rather similar results, at least for the mean volume target variables. Besides the cluster distance, we assume that REs also depend on the study region; its size and variability in conditions and forest characteristics. Even though our observations are not generalizable as such, it is worth noticing and considering these aspects in similar types of studies.

In agreement with many previous studies (e.g., Stevens Jr and Olsen 2003; Grafström and Schelin 2014; Magnussen et al. 2020), our results demonstrate that the SRS variance estimator fails to reveal improved precision due to spatially balanced sampling and that local difference estimators are much less biased. In the case of LPMxy, local difference estimators never underestimated the true sampling variance. A guarantee against variance underestimation is important from the practical point of view: we do not want to end up claiming our estimators to be more precise than they really are.
For systematic sampling, the Grafström-Schelin variance estimates were practically identical to the Matérn estimates. This finding lends support to the use of Grafström-Schelin estimator for spatially systematic samples other than rectangular grids, for which the Matérn estimator is not directly applicable. This is relevant, for example, in Finnish NFI, where the sampling design has evolved from a square grid of clusters to a combination of two different grids, one for permanent sample plots and another for temporary plots. Irregular designs also occur, when the estimation is needed over period with partial samples from two consecutive inventories with different systematic designs.

In LPM designs with further auxiliary variables in addition to the geographic coordinates, we found that the Grafström-Schelin estimator tended to underestimate the sampling variance for the subpopulations. This phenomenon may be associated with the domain estimation context (LPM sampling was conducted at the level of the whole population). Some support for this hypothesis was obtained from a spot test, where we generated LPM samples with all auxiliary variables from subpopulation 2. The Grafström-Schelin variance estimates for the 'All volume' were at the same level as those computed from the whole-population LPM samples, but the empirical variance of volume estimates was so much smaller that significant underestimation did not occur.

In the case of cluster sampling designs such as here, there is potential for improvement in the definition of the neighborhood for LPM sampling and the GrafströmSchelin variance estimator. The Euclidean distance metric based on cluster-level mean values of the auxiliary variables could be replaced by another metric that would also reflect within cluster variation. For example, cluster-level quantiles of auxiliary variables could be used to identify the most similar cluster. This could affect the efficiency of the LPM algorithm, as very different plot combinations could produce exactly the mean volume within the cluster.

\section{Conclusions}

According to our simulation study, LPM designs utilizing auxiliary data can be more efficient than systematic sampling for specific target variables, but it appears to be difficult to make gains in efficiency simultaneously for all target variables of an NFI. In our study, we included thirteen different target variables and for some of them the LPM designs were less efficient than the systematic sampling design. All in all, to make gains in efficiency using LPM, for some target variables it might be necessary to accept smaller efficiencies for other target variables. Nevertheless, even though the use of LPM as a general tool in an NFI seems challenging, it enables unequal probability sampling and fixed-size samples with 
an approximate spatial balance, which may be useful when designing a special inventory.

In the systematic design, the Grafström-Schelin estimator of variance was practically equivalent to the Matérn estimator applied in the Finnish National Forest Inventory. Both are easy to implement in an operational NFI, but the Grafström-Schelin estimator is more flexible, since it is also directly applicable to geographically balanced designs other than rectangular grids. However, we found that the Grafström-Schelin estimator can underestimate true sampling variance in subpopulation estimates when LPM is applied with other auxiliary data in addition to the coordinates.

\section{Supplementary information}

Supplementary information accompanies this paper at https://doi.org/10. 1186/s40663-020-00266-9.

Additional file 1: Table S1. Simulation results in national forest inventory field plot populations (field) and multi-source national forest inventory populations (1-nn) with different sampling designs and variance estimators.

\section{Abbreviations}

LPM: Local pivotal method; MS-NFI: Multi-source national forest inventory; NFI: National forest inventory; NFI11: The 11th national forest inventory; RE: Relative efficiency; SRS: Simple random sampling; vsb: Grafström-Schelin variance estimator

\section{Acknowledgements}

Not applicable.

\section{Authors' contributions}

All authors participated in planning the study. KM constructed the 1-nn forest resource map. MK implemented the analysis. MR prepared the original draft. All authors reviewed and edited the draft and approved the final manuscript. JH and MM supervised the work. AK and MM handled the project administration and funding acquisition.

\section{Funding}

The financial support for this study was provided by the Ministry of Agriculture and Forestry key project "Puuta liikkeelle ja uusia tuotteita metsästä" ("Wood on the move and new products from forest") and Academy of Finland (project numbers 295100 and 306875).

\section{Availability of data and materials}

Parts of the data that support the findings of this study are available from the corresponding author upon reasonable request.

\section{Ethics approval and consent to participate}

Not applicable.

\section{Consent for publication}

Not applicable.

\section{Competing interests}

The authors declare that they have no competing interests.

\section{Author details}

${ }^{1}$ Natural Resources Institute Finland (Luke), PO Box 2, Fl-00791 Helsinki, Finland. ${ }^{2}$ Natural Resources Institute Finland (Luke), Yliopistokatu 6, Fl-80100 Joensuu, Finland.
Received: 4 March 2020 Accepted: 25 August 2020

Published online: 24 September 2020

\section{References}

Bezanson J, Edelman A, Karpinski S, Shah VB (2017) Julia: a fresh approach to numerical computing. SIAM Rev 59(1):65-98. https://doi.org/10.1137/ 141000671

Cochran WG (1977) Sampling techniques, 3rd edn. Wiley, New York

Ene LT, Næsset E, Gobakken T, Gregoire TG, Ståhl G, Holm S (2013) A simulation approach for accuracy assessment of two-phase post-stratified estimation in large-area LiDAR biomass surveys. Remote Sens Environ 133:210-224. https:// doi.org/10.1016/j.rse.2013.02.002

FAO (2012) Forest Resources Assessment 2015: Terms and Definitions. http:// www.fao.org/docrep/017/ap862e/ap862e00.pdf. Accessed 1 Feb 2019

Grafström A, Lundström NLP (2013) Why well spread probability samples are balanced. Open J Stat 03(01):36-41. https://doi.org/10.4236/ojs.2013.31005

Grafström A, Lundström NLP, Schelin L (2012) Spatially balanced sampling through the pivotal method. Biometrics 68(2):514-520. https://doi.org/10. 1111/j.1541-0420.2011.01699.x

Grafström A, Matei A (2018) Spatially balanced sampling of continuous populations. Scand J Stat. https://doi.org/10.1111/sjos.12322

Grafström A, Ringvall AH (2013) Improving forest field inventories by using remote sensing data in novel sampling designs. Can J For Res 43:1015-1022. https://doi.org/10.1139/cjfr-2013-0123

Grafström A, Schelin L (2014) How to select representative samples. Scand J Stat 41(2):277-290. https://doi.org/10.1111/sjos.12016

Grafström A, Zhao X, Nylander M, Petersson H (2017) A new sampling strategy for forest inventories applied to the temporary clusters of the Swedish NFI. Can J For Res 47:1161-1167. https://doi.org/10.1139/cjfr-2017-0095

Gregoire TG (1998) Design-based and model-based inference in survey sampling: appreciating the difference. Can J For Res 28(10):1429-1447. https://doi.org/ 10.1139/x98-166

Gregoire TG, Ran G, HI S, Næsset E, Gobakken T, Nelson R, Ren Holm S (2011) Model-assisted estimation of biomass in a LiDAR sample survey in Hedmark County, Norway. Can J For Res 41:83-95. https://doi.org/10. 1139/X10-195

Haakana H, Heikkinen J, Katila M, Kangas A (2019) Efficiency of post-stratification for a large-scale forest inventory - case Finnish NFI. Ann Forest Sci 76(1):9. https://doi.org/10.1007/s13595-018-0795-6

Heikkinen J (2006) Chapter 10: assessment of uncertainty in spatially systematic sampling. Kangas a, Maltamo M (eds) Forest inventory: methodology and applications, managing Forest ecosystems (book 10). Springer Netherlands. Pp 155-178. https://doi.org/10.1007/1-4020-4381-3

Kangas A, Astrup R, Breidenbach J, Fridman J, Gobakken T, Korhonen KT, Maltamo M, Nilsson M, Nord-Larsen T, Næsset E, Olsson H (2018) Remote sensing and forest inventories in Nordic countries - roadmap for the future. Scand J Forest Res 33(4):397-412. https://doi.org/10.1080/02827581.2017.1416666

Kangas A, Myllymäki M, Gobakken T, Næsset E (2016) Model-assisted forest inventory with parametric, semiparametric, and nonparametric models. Can J For Res 46:855-868. https://doi.org/10.1139/cifr-2015-0504

Langsaeter A (1926) Om beregning av middelfeilen ved regelmessige linjetaksering (in Norwegian). Meddel fra det norske Skogforsøksvesen 2(7):5-47

Lindeberg JW (1924) Calculating the standard error in the strip-survey results (in German). Acta Forest Fenn 25(5): article id 7080. Doi:https://doi.org/10.14214/ aff.7080

Lisic J, Grafström A (2018) SamplingBigData: sampling methods for big data. R package version 1.0.0. https://cran.r-project.org/package=SamplingBigData. Accessed 1 Feb 2019

Magnussen S, Andersen HE, Mundhenk P (2015) A second look at endogenous poststratification. For Sci 61(4):624-634. https://doi.org/10. 5849/forsci.14-183

Magnussen S, McRoberts RE, Tomppo EO (2009) Model-based mean square error estimators for k-nearest neighbour predictions and applications using remotely sensed data for forest inventories. Remote Sens Environ 113(3):476488. Elsevier B.V. https://doi.org/10.1016/j.rse.2008.04.018

Mäkisara K, Katila M, Peräsaari J (2019) Multi-Source National Forest Inventory of Finland - methods and results 2015. Natural resources and bioeconomy studies 8/2019, Helsinki

Matérn B (1947) Methods of estimating the accuracy of line and sample plot surveys. Meddelanden från Statens Skogsforstkningsinstitut 36(1):138 
Matérn B (1960) Spatial variation. Stochastic models and their application to some problems in forest surveys and other sampling investigations. Meddelanden från Statens Skogsforskningsinstitut 49(5): 144

McRoberts RE, Næsset E, Gobakken T (2013) Inference for lidar-assisted estimation of forest growing stock volume. Remote Sens Environ 128:268-275. https:// doi.org/10.1016/j.rse.2012.10.007

Myllymäki M, Gobakken T, Næsset E, Kangas A (2017) The efficiency of poststratification compared with model-assisted estimation. Can J For Res 47(4):515-526. https://doi.org/10.1139/cjfr-2016-0383

Opsomer JD, Jay Breidt F, Moisen GG, Kauermann G (2007) Model-assisted estimation of forest resources with generalized additive models. J Am Stati Assoc 102(478):400-409. https://doi.org/10.1198/016214506000001491

R Core Team (2018) R: a language and environment for statistical computing. R Foundation for Statistical Computing, Vienna. https://www.r-project.org/. Accessed 8 Mar 2019

Rao CR (1973) Linear statistical inference and its applications, 2nd edn. Wiley, New York

Räty M, Heikkinen J, Kangas AS (2018) Assessment of sampling strategies utilizing auxiliary information in large-scale forest inventory. Can J For Res 48(7):749757. https://doi.org/10.1139/cjfr-2017-0414

Räty M, Kangas AS (2019) Effect of permanent plots on the relative efficiency of spatially balanced sampling in a national forest inventory. Ann Forest Sci 76(1):20. https://doi.org/10.1007/s13595-019-0802-6

Roberge C, Grafström A, Ståhl G (2017) Forest damage inventory using the local pivotal sampling method. Can J For Res 47(3):357-365. https://doi.org/10. 1139/cjfr-2016-0411

Saarela S, Schnell S, Grafström A, Tuominen S, Nordkvist K, Hyyppä J, Kangas A, Ståhl G (2015) Effects of sample size and model form on the accuracy of model-based estimators of growing stock volume. Can J For Res 45:15241534. https://doi.org/10.1139/cjfr-2015-0077

Salminen S (1973) Tulosten luotettavuus ja karttatulostus valtakunnan metsien V inventoinnissa (in Finnish). Summary: reliability of the results from the fifth national forest inventory and a presentation of an output- mapping technique. Comm Inst Forest Fenn 78(6):64

Särndal C-E, Swensson B, Wretman J (1992) Model assisted survey sampling. Springer-Verlag Publishing, New York. https://doi.org/10.1007/978-1-46124378-6

Ståhl G, Saarela S, Schnell S, Holm S, Breidenbach J, Healey SP, Patterson PL, Magnussen S, Næsset E, Mcroberts RE, Gregoire TG (2016) Use of models in large-area forest surveys: comparing model-assisted, model-based and hybrid estimation. Forest Ecosyst 3:5. https://doi.org/10.1186/s40663-016-0064-9

Stevens DL Jr, Olsen AR (2003) Variance estimation for spatially balanced samples of environmental resources. Environmetrics 14(6):593-610. https://doi.org/10. 1002/env.606

Tipton J, Opsomer J, Moisen G (2013) Properties of endogenous post-stratified estimation using remote sensing data. Remote Sens Environ 139:130-137. https://doi.org/10.1016/j.rse.2013.07.035

Tomppo E, Gschwantner T, Lawrence M, McRoberts RE (2010) National Forest Inventories: pathways for common reporting. Springer. https://doi.org/10. 1007/978-90-481-3233-1

Tomppo E, Haakana M, Katila M, Peräsaari J (2008) Multi-source National Forest Inventory - methods and applications. Series: managing Forest ecosystems 18. Springer. https://doi.org/10.1007/978-1-4020-8713-4

Tomppo E, Halme M (2004) Using coarse scale forest variables as ancillary information and weighting of variables in k-NN estimation: a genetic algorithm approach. Remote Sens Environ 92:1-20. https://doi.org/10.1016/j. rse.2004.04.003

Tomppo E, Heikkinen J, Henttonen HM, Ihalainen A, Katila M, Mäkelä H, Tuomainen T, Vainikainen N (2011) Designing and conducting a Forest inventory - case: 9th National Forest Inventory of Finland. Springer, Netherlands

Tomppo E, Katila M, Mäkisara K, Peräsaari J (2014) The multi-source Nationa Forest Inventory of Finland - methods and results 2011. Working papers of the Finnish Forest research institute 319

Vidal C, Alberdi IA, Hernández Mateo L, Redmond JJ (2016) National Forest Inventories - assessment of wood availability and use, 1st edn. Springer International Publishing, Cham. https://doi.org/10.1007/978-3-319-44015-6

Wolter KM (1984) An investigation of some estimators of variance for systematic sampling. J Am Stat Assoc 79(388):781-790. Taylor \&Francis. https://doi.org/ 10.1080/01621459.1984.10477095

\section{Submit your manuscript to a SpringerOpen ${ }^{\circ}$ journal and benefit from:}

- Convenient online submission

- Rigorous peer review

- Open access: articles freely available online

- High visibility within the field

- Retaining the copyright to your article

Submit your next manuscript at $\boldsymbol{\nabla}$ springeropen.com 